\title{
Research on Financing Mode and Risk Prevention of Supply Chain in Small and Medium - sized Enterprises
}

\author{
Hangyu $\mathrm{Xu}^{1, \mathrm{a}}$ \\ ${ }^{1}$ Gabelli School of Business, Fordham University, New York 10023, USA \\ axuhalu@yahoo.com
}

Keywords: small and medium-sized enterprises, supply chain, financing model, risk prevention

\begin{abstract}
On the basis of introducing the basic model of supply chain financing of small and medium-sized enterprises(SME), this paper analyzes the credit risk, operational risk and market risk faced by its supply chain financing. Furthermore, this paper analyzes the formation mechanism of the three kinds of risks faced by small and medium-sized enterprises. Finally, this paper puts forward some countermeasures and suggestions on how to prevent the credit risk, operational risk and market risk faced by the supply chain financing of small and medium-sized enterprises.
\end{abstract}

\section{The basic model of small and medium enterprises supply chain financing}

The so-called supply chain is the process of connecting the (intermediate link and topmost) supplier to the (intermediate link and lowest level) user, which is the process of increasing the value of the firm and the starting point of the supply and the end of the consumption. In general, the abbreviation of financing for enterprises is financing, which includes the integration and financing of funds, that is "two-way interaction process." The "supply chain financing" refers to a way of financing that the bank considers the supply chain on the main body as a whole, according to the real business transactions between the relevant funds and funds into the supply chain financing.

1.1 SME supply chain financing in China's development. In view of China's current economic development, supply chain financing is still in the initial stage, from the development model of financing that can be used for Chinese enterprises to learn from the model is very limited. At the same time, various commercial banks are combining their own advantages, the development of their own advantages related to the financing of products.

First of all, Shenzhen Development Bank in 2006 launched the "supply chain financing" after the brand, the innovative proposed "self-financing trade financing" and " $1+\mathrm{N}$ " supply chain financing, which made it the industry benchmark. By 2010, the entire financing process of the supply chain had associated financing products, such as steel, coal and rubber, more than 20 different industries. Shanghai Pudong Development Bank took "supply chain financing solutions" as its concept, introduced a series of new financing products in the "supply chain financing" business. In February 2012, CITIC Bank also launched the "electronic supply chain finance" online supply chain financing services, which ushered in the online "revolution", online supply chain financing officially joined the ranks of market competition.

1.2 Characteristics of supply chain financing model for small and medium-sized enterprises. Supply chain financing model, which does not consider the needs of a single business, but consider all the needs of enterprises involved from the overall. Its characteristics are as follows:

1.2.1 Taking the supply chain as a whole for the credit object. In the supply chain financing, the banks' the majority of small and medium enterprises credit business is the financial characteristics of the supply chain with the most closely integrated business. As the core enterprises in the supply chain in the financing has the general financing channels and low financing costs, which cannot significantly reduce the cost of its supply chain in the supply chain financing, so there is no essential difference for the core business with traditional enterprises in the credit. However, the costs incurred by small and medium-sized enterprises in the financing process can be effectively controlled through supply chain financing, thereby it achieves the costs of reducing the overall financing process associated with supply chain financing. 
The traditional way of credit mainly considers the financial status of the enterprise, the way of guarantee and the credit level of the main body. From the perspective of a single enterprise, due to the high non-systemic risk and default risk of small and medium-sized enterprises, the credit market often excluded small and medium enterprises. Banks introduce the concept of "structural credit" into supply chain financing, that is, the real trade in the supply chain as the background, co-credit the supply chain loan applicants and the main participants. The bank provides different Financing products for different customer groups, small and medium enterprises with the supply chain as a whole of the credit strength, so that banks to reduce the restrictions on their, so as to obtain the necessary funds. At the same time, the structure of credit also increased the efficiency of bank credit funds, and strict access to the supply chain system, through the debt rating system, credit bundling technology, greatly reducing and diversifying the risk.

1.2.2 Emphasis on trade background. In the supply chain financing, the main source of repayment is the three kinds of liquidity assets, namely, accounts receivable, advance receipts and inventory. How to protect the three assets of the repayment ability in the maturity period before the credit period: first of all, the banks should pay more attention to the advance receipts and accounts receivable, because the two closely linked to the financial situation with the supply chain in the upstream and downstream credit, financial status of the most. Therefore, the assessment of corporate credit risk should from the real trade of the supply chain. Banks should not only pay attention to the financial statements of small and medium enterprises, but also should concern about the upstream and downstream business relationship between the transaction and payment and other real trade background, so as to ensure that what enterprises used to repay the funds is from its sales revenue, and to ensure that funds are not misappropriation, in order to achieve the banks' overall control of the supply chain.

1.2.3 Self-sufficiency of corporate finance. The self-sufficiency of corporate finance has a very typical characteristic of self-sufficiency, mainly because the financing firms use the sales income of the trade, rather than making full use of prepaid and receivable way to repay. The self-financing trade financing business has important value and unlimited market potential relative to the traditional concept of borrowing. It has the advantages of self-sufficiency of repayment sources, closeness of operation, risk control means and credit use, both have great breakthrough and innovation. In order to effectively assess and control risk, it is important not only to focus on isolated subjects, but also to pay attention to their financial situation for self-financing trade finance. This feature of self-financing trade finance is of great importance to the financing of small and medium-sized enterprises. Small and medium-sized enterprises generally small size, poor business stability, the report is not real, which not only led to its financing difficulties, the results also make the bank's traditional financial analysis technology to prevent the bank's decision-making for small and medium enterprises credit. Therefore, taking the real business of the enterprise as the background, through the integration of the entire supply chain, which can not only reduce the risk of banks, but also can ease the financing problems of SMEs.

\section{Identification risks of Small and medium enterprises supply chain financing model}

Modern project management believes that the project is an organization to achieve the established goals. In a certain time, personnel and other resources under the constraints of the conditions carried out by a certain unique, one-time work. The process of project risks management is divided into three steps: risk identification, risk assessment and risk control. Based on the definition and characteristics of supply chain financing risk, project management theory can be used to study it, and the theoretical basis of supply chain financing risk identification is derived from the risk identification in project risk management.

2.1 Identification of credit risk. Credit risk identification is to find the main reason for corporate default. Firstly, credit risk can be divided into systemic and non-systemic risk. Systematic risk refers to the common factors that affect the loss of most companies in the industry. As the financing is related to the supply chain in the upstream and downstream enterprises, so the bank must firstly consider the system risk. Systematic risk can be considered from both macro and industry 
perspectives. It is important to note that banks need to assess the systemic risk of the core business in the supply chain. Non-systemic risk is the risk that individual firms are caused by their own factors. Although the supply chain financing in the financing of enterprises and core enterprises have a stable business relationship, reducing the non-systemic risk to a certain extent. However, the enterprise's own factors will directly affect the enterprise's ability to repay and willingness. Banks need to establish a sound loan system, and rely on the core business and third-party logistics enterprises to assist in monitoring the risk of timely warning. Secondly, the supply chain financing assets are inventory, advance receipts and accounts receivable. In order to protect the repayment ability of these assets, enterprises should not only have itself assessment, but also should consider the main business qualification and property status. Finally, the moral hazard generated by the financing enterprises should also be examined.

2.2 Identification of operational risk. Banks can establish their own supply chain financing for the operation of the risk of the directory based on the Basel Committee operational risk classification, and constantly sum up and analyze their own mistakes, update the operational risk catalog timely, making the operational risk identification more perfect and mature. Therefore, risk management can be carried out according to the operational aspects of supply chain financing.

Table 1 supply chain operation risk of each operation process

\begin{tabular}{|l|l|}
\hline Operational process & Potential risks \\
\hline Credit investigation & $\begin{array}{l}\text { Taking business transaction information as the basis, high } \\
\text { professional requirements, likely to cause customer manager } \\
\text { misjudgment }\end{array}$ \\
\hline Product design & $\begin{array}{l}\text { Due to the contract is not perfect or the product process design } \\
\text { unreasonable and increase the probability of operational risk }\end{array}$ \\
\hline \multirow{2}{*}{ Financing approval } & $\begin{array}{l}\text { The risk of the approval process, the bank approval process caused } \\
\text { by unreasonable internal control system chaos }\end{array}$ \\
\cline { 2 - 2 } & $\begin{array}{l}\text { Personnel risk, such as internal fraud and overriding, etc.; subjective } \\
\text { risks, such as loss of key positions }\end{array}$ \\
\cline { 2 - 2 } & $\begin{array}{l}\text { System risks, systems or models for background risk management } \\
\text { fail to identify risks effectively }\end{array}$ \\
\hline $\begin{array}{l}\text { Account and credit } \\
\text { management }\end{array}$ & $\begin{array}{l}\text { Such as warehouse staff dereliction of duty or fraud and other } \\
\text { reasons caused by external risks }\end{array}$ \\
\hline
\end{tabular}

2.3 Identification of market risk. For some reason, causing fluctuations of market prices, exchange rates and others, market risks could result in the risk of changes in the price of collateral. The risk identification of supply chain financing can be based on factors that cause market risk to carry out risk identification, such as policy, law and exchange rate changes.

\section{Formation mechanism of small and medium enterprises supply chain financing model risks}

Loan supply chain risk is an objective reality, in this process, supply chain financing brings economic benefits at the same time, however it is always accompanied by a certain risk. In the supply chain system, commercial banks, as member of the credit business flow, participate in changes of material flow and information flow, therefore the expected benefits of commercial banks are uncertain. The fundamental risk control measures of commercial banks should correctly understand the effectiveness of risk decision-making in order to control the risks. Correctly identify the risks of the supply chain business mainly include two elements: firstly, to determine the risk of supply chain financing business; secondly, to find out the cause of sending some risk. Successful 
identification of the source of supply chain financing risk and its driving force is the key to manage the financing risk of supply chain, which is of great significance to the smooth development of supply chain financing business.

3.1 Credit risk. In the supply chain financing, small and medium enterprises want bank loans as a financier, but cannot repay the repayment of the supply chain financing agreement to repay all or part of the funds. This makes the financial providers, such as commercial banks and other financial institutions, bear the risk. First of all, commercial banks and other financial institutions for small and medium enterprises are not willing to meet the demand for loans, not because of that the size of its company is too small or the rule of governance is not standardized and other issues. But for the reason that small and medium enterprises are very easy because of information asymmetry, credit also result in the lack of credit. In addition, this kind of information asymmetry also affects the financing business participants, small and medium-sized financing enterprises and commercial banks are not equal, there is a deviation. To sum up the reasons, credit risk has become the main impact of supply chain financing risk.

One of the systemic risk is the credit risk that all enterprises in the economy will generally bear, and the loss of the majority of the enterprises in the market due to changes in the external environment, such as changes in the business cycle and the downturn in the industry. In supply chain financing, the main source of systemic risk is the supply chain itself or the core business in the supply chain. Therefore, we should pay attention to the operation of core enterprises and financial changes, because the core business status is strongly leading the overall operation of the supply chain. The system risk in the supply chain mainly has the following two aspects. On the one hand, there are many nodes in the supply chain business and existing endogenous chaos for the objective existence of uncertainty. In the supply chain financing business, the participation of the main body is more and more affected by the internal and external factors are more complex, and the interaction between the various subjects are likely to cause confusion and uncertainty, becoming endogenous risks of the business objective existence. On the other hand, the overall risk of the supply chain will spontaneously spread, with the use of financing products extending its upstream and downstream supporting enterprises. Even if there is a core enterprise in the supply chain that plays a supporting role, a node of the enterprise's shortage of funds risk will also spread to other direction of the node business, until they spread to the entire supply chain.

3.2 Operational risk. In 1996, the Basel Commercial Bank Regulatory Commission promulgated the "Supplementary Provisions on Market Agreements on Market Agreements", which defines operational risk as a result of the lack of internal control, human error, system failure, and external events that cause commercial banks loss, loss includes all costs associated with risk events. Due to bank failure or imperfect internal control, system barriers, human error and related external factors both cause losses for commercial banks.

Operational risk is the main risk category of supply financing, its costs mainly associated with risk events. As the banking system is relatively mature, although the frequency is relatively low, but it would occasionally lead to economic losses which are more serious. Supply chain non-node enterprises have their own trading characteristics, commercial banks make their customized financial products based on different characteristics of the enterprises. The key for supply of information flow is that the flow of funds between individual participation and fiscal discipline and supply chain risk control between the contract logistics. Due to the large number of participants in the supply chain, the information transmission is complicated, and the operational risk is also increased.

3.2.1 Credit process risk factors. Supply chain financing operation process is too complex and will lead to the probability of occurrence of operational risk increases, the control of assets loopholes caused by complex links and the implementation of difficulties are the main reason leading to operational risk. During the process of financing approval, the credit approval process is unreasonable, the internal control system is not properly distributed due to improper authorization, and the relevant information transmission is not timely, all of which will lead to the occurrence of operational risk. 
3.2.2 Operator operating risk factors. In the financing survey stage, the traditional supply chain credit investigation where there is a difference in the credit loan business, it is required that staff's professional knowledge is relatively high, otherwise it is likely to lead to the operator's wrong judgment or omission. Financing of the approval stage, the staff would prone to ultra vires due to be perfect for the operation of the internal control system, thus resulting in internal fraud risk, making the operator's service quality becomes low. In addition, the operator's lack of professional knowledge, lack of capacity, the same post-loan management stage of the loss caused by work, fraud and reading may bring operational risks.

3.2.3 System operating risk factors. In the process of supply chain finance operation, the main reason for the risk control of assets due to the complicated operation is the difficulty of the credit approval process, the unreasonable approval process, the internal control system is improper authorization, and generate operational risk based on the delay of information transmission.

3.3 Market risk. Market risk is due to interest rates, exchange rates, changes in commodity prices, as a result the possibility of loss of commercial banks mainly for supply chain enterprises inventory pledge value, including the price of collateral market fluctuations, the financial exchange rate changes in liquidity. Due to the macroeconomic environment, commodity prices, changes in bank exchange rate, it would lead to the potential for damage to banks. In the supply chain financing, mainly in the enterprise pledged value-added hedge. Involving changes in the price of collateral in the trading market, a series of collateral liquidity performance deterioration would cause exchange rate fluctuations. In the case of inventory financing, for example, commercial banks firstly determine that whether they have sufficient control over the collateral to grant credit to small and medium enterprises. The change in the value of these collateral in the market has brought the market to the market, and this property control of the goods dominated by the financing model is more likely to bear the risk in the market. There are many factors that affect the value of collateral, such as product quality damage, technological upgrading, capital inflow and so on. Once the value of the collateral has been deviated by the factors, the default risk of the customer will become larger, third-party logistics companies and commercial banks will suffer economic losses.

\section{Risk prevention for small and medium enterprises supply chain financing model}

4.1 Risk management measures for credit risk. Due to the large number of participants in the supply chain financing, the credit status is different, and the main demand for financing funds is small and medium enterprises and its credit is the most serious, so the credit risk in supply chain financing cannot be avoided, it is necessary to strengthen the credit risk management. Risk management measures for credit risk are:

4.1.1 Establish credit risk assessment system to strengthen the enterprise's credit management. In the supply chain financing, the credit risk of the financing enterprise is the largest, so the banks must carry on the strict credit investigation to the financing enterprise before carrying out the supply chain financing business. And because of the particularity of the business and the bank must determine the operation of the entire supply chain and the core business situation review. To sum up, commercial banks should establish a special assessment of its assessment to avoid the supply chain financing credit risk, so as to carry out credit management for related enterprises. The bank should first investigate the credit records of the financing firms in the supply chain and the repayment situation. These credit records will directly lead to the possibility of the credit risk of the financing enterprises. Secondly, the banks can review the basic qualities of those who decide the moral hazard of the financing enterprises, such as corporate governance structure, leadership and staff quality, firm size and rules and regulations. Thirdly, the bank should determine their financial reporting capacity through the review of the supply chain financing companies. In addition, the bank through the review of financing enterprises and core enterprises' relevance of production products and its brand effect in the industry, the status in the supply chain, analyzing the potential and prospects of financing enterprises, thus to a certain extent, reduce the enterprise's credit risk.

4.1.2 Choose third-party logistics enterprises with the good credit and strength. In the supply chain financing, there are many participations in the main bodies, which are easy to cause 
information asymmetry; third-party logistics enterprises through the integration of the supply chain, to a certain extent, can assess the size of credit risk. Therefore, in cooperation with third-party logistics enterprises, the best choices are companies with good credit and strength. As the current domestic logistics industry standards and industry standards are not clear, so the banks should carefully choose the object of cooperation. Good credit is the primary criterion for choosing a cooperative logistics business, which is good credit because good credit history can reduce the problems which are posed by moral hazard and adverse selection. Second, in order to transfer the risk of logistics enterprises the banks should review the solvency, profitability and operational capacity. Third, the best choice for banks in the industry are the logistics business with good reputation and financial strength. These logistics companies are characterized by large customer base, industry wide, to a large extent, expand the scope of business banking. In addition, the logistics staff should also have a warehouse management, risk management and other related professional knowledge.

4.1.3 Monitor the operation of financing enterprises and core enterprises, dynamically control credit risk. Because of the national macroeconomic policy control and the emergence of new technologies and other factors, it prone to cause credit risk. In order to dynamically control credit risk, banks should monitor the operation of financing enterprises and core enterprises. In order to understand the market demand situation and grasp the market price of the product, they should collect the spot and futures prices of the product; in order to understand the raw materials and understand the market demand, in addition to monitoring the financing business and the core business, procurement and product sales, banks should also keep track of the upstream and downstream enterprises in the market situation. In addition, banks should ask companies to submit financial statements on a regular basis in order to keep abreast of business conditions. In addition to timely monitoring the operation of financing enterprises and core enterprises, banks should also take emergency measures to control the credit risk dynamics. If the financing companies had operating problems, banks should promptly adjust the pledge rate, requiring the increase in guarantor or margin, to strengthen repayment and other measures. If the core business had operation problems, banks should inform the affiliated enterprises to prevent and focus on the status of financing enterprises to prevent the emergence of a chain reaction.

4.1.4 Design credit process scientifically and strengthen the management of bank staff. In the supply chain financing, credit risk is often incurred due to loopholes in the credit process or the negligence of bank staff. Therefore, scientifically design credit process and strengthen the management of bank staff is the inevitable requirement to control the credit risk. In order to prevent the credit risk from the root cause, the bank should consider the following two aspects: First, in the process design, the bank should ensure that at least two or more staff members in any process and that there are no loopholes in the process of designing the credit process. Audit confirmation; strict control of authority. Second, the bank should organize the relevant staff to learn, to strengthen the incentive.

4.1.5 Establish information platform to achieve information sharing. The main reason for the credit risk is information asymmetry. In supply chain financing, credit risk will be greater due to the large number of participants, information asymmetry. Information asymmetry caused by poor flow of information also affect the normal operation of logistics and capital flows. In order to ensure the normal circulation of the supply chain and realize the information sharing of the logistics and capital flow, the banks should join the parties to participate in the main body to establish the information technology platform. With the help of the information technology platform, on the one hand, the bank monitors their credit risk through the understanding of the financing enterprises and core business logistics and capital flow, thus eliminating the information asymmetry and adverse selection problem; on the other hand, the bank can establish information sharing with logistics enterprises for credit risk management and monitoring.

4.2 Risk management measures for operational risk. As the supply chain financing model is different, many main bodies involved in business and process is complex, so the management of operational risk is very important. Risk management measures for operational risk are: 
4.2.1 Improve the contract, protocol and operational process design, standardize the operation. In the supply chain financing model, the contract, agreement, and operational processes do not form a uniform standard, often a set of contracts and processes, without the formation of standardized contract terms and processes, and are prone to operational risk. In order to avoid the operational risk, commercial banks should combine the case, identify the loopholes, establish a standard operational procedure, standardize the behavior of staff in order to achieve the possibility of reducing operational risk.

4.2.2 Form professional teams. As the supply chain financing model is more and more involved in the main business and process is complex, therefore, the quality of commercial bank staff is higher, banks should strengthen the training of its quality, training its expertise to avoid risk purposes.

4.2.3 Improve the internal control system and build a hierarchical supervision system. As the main body, such as the financing enterprises, bank staff, logistics enterprises to participate in the operation process, they often produce operational risk. Therefore, in order to solve operational risks, banks should improve the internal control system, build a multi-level supervision system.

4.2.4 Strengthen the management of credit and custody management. Pledge management is one of the most concentrated aspects of operational risk. One of the factors that determines the risk of supply chain is the level of custody management, so banks should focus on strengthening the management of pledge. In the supply chain financing, the pledge is generally the third-party logistics enterprises that responsible for storage and supervision. Banks should carefully select third-party logistics enterprises, and strengthen the logistics enterprises with the exchange of information and supervision of its pledge management at any time sampling.

\subsection{Risk management measures for other risks.}

4.3.1Risk management measures for market risk. In the supply chain financing, due to market supply and demand, interest rates, exchange rates, complementary or alternative price fluctuations and other factors cause a series of market risks, and market risk for banks is not controllable risk, therefore, to its risk management banks should: (1) choose the price which is relatively stable collateral; (2) and commodity prices are relatively stable industry cooperation; (3) establish one flexible and rapid commodity market price monitoring system ; (4) reasonably use of market risk transfer measures.

4.3.2 Risk management measures for policy risk. Policy risk management is targeted at the national macroeconomic policy, because the national macroeconomic policy for the bank is uncontrollable. Therefore, commercial banks in the management of policy risks predict the national macroeconomic policy only by grasping the market situation at any time to. In the event of policy risk, banks can take timely and risky measures to avoid large-scale risks.

\section{Conclusion}

This paper introduces the development of basic model of supply chain financing in China and its basic characteristics at first, and then identifies the credit risk, operational risk and market risk faced by its financing. Furthermore, this paper makes a comprehensive and systematic analysis of the formation mechanism of the three risks faced by small and medium-sized enterprises. Finally, this paper puts forward some countermeasures and suggestions on how to prevent the credit risk, operational risk and market risk faced by the supply chain financing of small and medium-sized enterprises.

\section{References}

[1] Lee S Y. Drivers for the participation of small and medium-sized suppliers in green supply chain initiatives[J]. Supply Chain Management: An International Journal, 2008, 13(3): 185-198. 
[2] Olson D L, Dash Wu D. A review of enterprise risk management in supply chain[J]. Kybernetes, 2010, 39(5): 694-706.

[3] Zsidisin G A, Ritchie B. Supply chain risk management-developments, issues and challenges[J]. Supply Chain Risk, 2009: 1-12. 